\title{
MRI Assessment of Extra-axial Findings at Pelvic Sites in a Group of Axial-SpA Patients
}

Fabio Massimo Perrotta (D) - Silvia Scriffignano (D) $\cdot$ Ennio Lubrano

Received: July 28, 2021 / Accepted: September 8, 2021 / Published online: September 20, 2021

(C) The Author(s) 2021

\section{ABSTRACT}

Introduction: MRI allows a better evaluation of inflammatory and structural lesions of the sacroiliac joints and spine in patients with axial spondyloarthritis (axial SpA), so MRI plays an important role in the classification and diagnosis of axial SpA. The aim of our study was to assess extra-axial MRI findings at pelvic sites and their possible associations with clinical indices in patients with axial SpA.

Methods: Axial-SpA patients who were classified according to the ASAS criteria and consecutively attended our clinic were assessed with pelvic MRI. The main clinical and demographic characteristics of all patients, including age, sex, BMI, presence of HLA-B27 and type of axial SpA (radiographic or nonradiographic), were evaluated. The main indices of disease activity and joint function were assessed, including BASDAI, ASDAS-PCR, BASMI and BASFI. Finally, the presence/absence of inflammatory/structural

F. M. Perrotta - S. Scriffignano - E. Lubrano ( $\square)$ Dipartimento di Medicina e Scienze della Salute "Vincenzo Tiberio", Università degli Studi del Molise, Via Giovanni Paolo II, C/da Tappino, 86100 Campobasso, Italy

e-mail: enniolubrano@hotmail.com lesions at extra-axial structures (the hip joints, pubic symphysis, greater and lesser trochanters, ischial tuberosity, iliac spines and iliac crest) was evaluated.

Results: 35 patients (21 males and 14 females) with a mean age (SD) of 47 (12.7) years and a mean duration of symptoms of 5 (2.1) years were enrolled. Hip abnormalities were found in 14 (40\%) patients. Trochanteric enthesopathy/ bursitis and pubic osteitis were found in 2 patients $(5.7 \%)$ and 1 patient $(2.8 \%)$, respectively. No other abnormalities were found at other sites. We found significant associations between the presence of extra-axial alterations, disease activity and joint function.

Conclusions: Our study demonstrated the presence of extra-axial abnormalities in more than one-third of patients with axial SpA, suggesting that MRI evaluation should be extended to the entire pelvis.

Keywords: Axial spondyloarthritis; MRI assessment; Enthesitis; Hip; Outcomes 


\section{Key Summary Points}

MRI assessment of the sacroiliac joints and spine is fundamental to the diagnosis, assessment and monitoring of axial-SpA patients.

MRI allows the examination of not only the sacroiliac joints and spine but the entire pelvis, with the possibility of evaluating extraspinal abnormalities.

MRI hip involvement was frequently seen in our group of axial-SpA patients, even in patients without clinical symptoms and with "early" disease. However, other entheseal sites do not seem to be frequently involved.

The presence of extra-axial lesions is associated with high disease activity and the worst function.

\section{INTRODUCTION}

Spondyloarthritis (SpA) is the collective term for a group of chronic inflammatory diseases that predominantly affect the axial skeleton. The Assessment of Spondyloarthritis International Society (ASAS) provides validated classification criteria for axial SpA, including both nonradiographic axial SpA (nr-axSpA) and ankylosing spondylitis (AS) [1]. The cornerstones of these classification criteria, which were developed to improve upon the sensitivity of the previous New York criteria for SpA and to allow early diagnosis, are the presence of HLA-B27 (a genetic biomarker) and bone marrow oedema at sacroiliac (SI) joints as assessed with magnetic resonance imaging (MRI) [2]. In particular, MRI assessment allows the evaluation of spinal, entheseal and articular inflammation and the possibility of detecting inflammation and structural abnormalities at spinal and sacroiliac joints, improving diagnostic confidence $[3,4]$.
However, patients with axial SpA may have peripheral joint involvement; in particular, clinically evident shoulder and hip involvement was observed in up to $30 \%$ of patients, decreasing articular function and quality of life [5]. Moreover, aside from the well-known involvement of Achilles tendon enthesis, few studies on the involvement of other extra-axial pelvic sites have been published. In particular, the presence of inflammation and/or structural lesions at other pelvic structures in patients with AS has been described $[6,7]$, but the clinical impact of the inflammation and/or lesions remains largely unclear, especially in the early phases of the disease. Also, bone structural changes do not tend to take place early in the course of the disease, and traditional assessment with radiographs may underestimate the frequency of involvement of hip and other pelvic structures, resulting in a diagnostic delay [7]. Moreover, the widespread use of MRI in patients with axial SpA for diagnostic, classification, assessment and monitoring purposes may make the evaluation of the involvement of other pelvic structures more feasible.

The aim of this study was to assess extra-axial MRI findings at pelvic sites and the possible associations of them with clinical activity and joint function in patients with axial SpA, based on MRI assessment of the pelvis.

\section{METHODS}

\section{Study Design}

This was a cross-sectional study conducted in an Italian tertiary referral rheumatology centre involved in clinical research on axial SpA. All procedures performed in studies involving human participants were carried out in accordance with the ethical standards of the institutional and/or national research committee and with the 1964 Helsinki Declaration and its later amendments or comparable ethical standards. Informed consent was obtained from all individual participants included in the study. The study was approved by the Institutional Review Board of the University of Molise. 


\section{Patient Selection}

Consecutive patients with axial SpA (as classified using the ASAS criteria [2]) who attended our clinic between 1 September 2020 and 31 March 2021 were assessed.

Exclusion criteria were:

1. Age $<18$ years

2. Recent $(<12$ months previously) pelvic trauma

3. Duration of symptoms $>10$ years.

Patient data, including age, sex, diagnosis (nr-axSpA and AS), disease duration, presence of extra-articular manifestations (EAM) (i.e. uveitis, inflammatory bowel diseases, psoriasis) and current comorbidities, were collected. The presence of tender (out of 68) and swollen (out of 66) joints, dactylitis and peripheral enthesitis was also evaluated. The disease activity indices used were the Bath Ankylosing Spondylitis Disease Activity Index (BASDAI) [8] and the Ankylosing Spondylitis Disease Activity Score (ASDAS) [9]. The degree of X-ray sacroiliitis according to the New York criteria (within 6 months from the visit) [10], the erythrocyte sedimentation rate $(\mathrm{ESR}, \mathrm{mm} / \mathrm{h})$ and the C-reactive protein (CRP) level $(\mathrm{mg} / \mathrm{dl})$ were also evaluated.

\section{MRI Assessment}

All patients underwent MRI of the SI joints and pelvis at the time of enrolment $( \pm 1$ month from thebaseline visit).

MRI of the SI joints and pelvis was performed with a 1.5 T MAGNETOM Verio scanner. MRI of the SI joints was performed using coronal T1weighted (T1WI) turbo spin echo (TSE) and T2WI TSE + STIR sequences. For each sequence, the field of view was $320 \mathrm{~mm}$ and the thickness of each slice was $4 \mathrm{~mm}$ with an interval of $1 \mathrm{~mm}$. Additionally, a STIR sequence was used to acquire 25 slices of the SI joints in a coronal plane parallel to the long axis of the SI joints; the thickness of each slice was $4 \mathrm{~mm}$. The presence of active inflammatory lesions (bone oedema) at SI joints was evaluated according to ASAS criteria [2]. The Spondyloarthritis
Table 1 Clinical, demographic and radiological features of the enrolled axial-SpA patients

\begin{tabular}{ll}
\hline Male/female & $21 / 14$ \\
Age in years, mean (SD) & $47(12.7)$ \\
Disease duration in years, mean (SD) & $5(2.1)$ \\
BMI, median (IQR) & $24.2(22-26.3)$ \\
Nr-axSpA (\%) & $15(42.9)$ \\
AS (\%) & $20(57.1)$ \\
Extra-articular manifestations, $n$ (\%) & \\
Uveitis & $6(17.1)$ \\
Psoriasis & $2(5.7)$ \\
Crohn's disease/ulcerative colitis & $5(14.2)$ \\
BASDAI, median (IQR) & $5(2-6.5)$ \\
ASDAS-CRP, median (IQR) & $2.8(1.7-3.3)$ \\
BASFI, median (IQR) & $5(1.5-6.3)$ \\
BASMI, median (IQR) & $2(0-4)$ \\
HLA-B27+ (\%) & $19(63.3 \%)^{\mathrm{a}}$ \\
CRP in mg/dl, median (IQR) & $0.5(0.3-1.2)$ \\
Treatment (\%) & \\
NSAIDs & $20(57.1)$ \\
csDMARDs & $4(11.4)$ \\
Biologic (anti-TNF, anti-IL-17A) & $13(37.1)$ \\
SPARCC, median (IQR) & $3(0-12)$ \\
\hline SD standad dian &
\end{tabular}

$S D$ standard deviation, $I Q R$ interquartile range, $B M I$ body mass index, $n r$-axSpA nonradiographic axial spondyloarthritis, $A S$ ankylosing spondylitis, BASDAI Bath Ankylosing Spondylitis Disease Activity Index, ASDAS Ankylosing Spondylitis Disease Activity Score, BASFI Bath Ankylosing Spondylitis Funtional Index, BASMI Bath Ankylosing Spondylitis Metrology Index, $C R P$ C-reactive protein, NSAIDs nonsteroidal anti-inflammatory drugs: conventional synthetic disease-modifying antirheumatic drugs, SPARCC Spondyloarthritis Research Consortium of Canada Scoring System

${ }^{a}$ HLA-27 not available for 5 patients

Research Consortium of Canada (SPARCC) MRI index was used to assess the presence of inflammatory lesions in the SI joints [11]. MRI 
Table 2 MRI findings for our axial-SpA patients

\begin{tabular}{ll}
\hline Finding & $n(\%)$ \\
\hline Presence of extraspinal pelvic involvement & $14(40)$ \\
Hip involvement & $14(40)$ \\
Hip effusion & $11(31.4)$ \\
Hip bone marrow oedema & $1(2.8)$ \\
Fat infiltration & $2(5.7)$ \\
Joint space narrowing & $4(11.4)$ \\
Erosion/sclerosis/ankylosing spondylitis & $0(0)$ \\
Enthesitis/trochanter bursitis & $2(5.7)$ \\
Pubic osteitis & $1(2.8)$ \\
Ischial tuberosity enthesitis & $0(0)$ \\
Enthesitis of the iliac spines and crest & $0(0)$ \\
\hline
\end{tabular}

of the pelvis was performed using transverse and coronal T1WI TSE and transverse and coronal T2WI TSE + STIR sequences in order to assess the presence/absence of inflammatory/ structural lesions at extra-axial structures (in particular, we aimed to evaluate the hip joints, pubic symphysis, greater and lesser trochanters, ischial tuberosity, iliac spines and iliac crest). In this study, we defined the hip MRI findings as previously described by Huang et al. [12].
The presence of subchondral bone marrow oedema, joint effusion, abnormal synovial enhancement or enthesitis on MRI was considered to be a marker of active inflammatory changes. Additionally, subchondral erosive destruction, joint space narrowing, fat infiltration, sclerosis and ankylosis were considered to be findings of chronic inflammatory changes. The MR images were evaluated by an expert radiologist blinded to the clinical features of the patients.

The patients were divided into two groups: those with no evidence of pelvis abnormalities outside the SI joints and those with at least one extra-axial finding. Differences between the two groups in disease activity and functional indices were evaluated.

The associations of the presence of extra-axial abnormalities with the main demographic and clinical variables were studied. In particular, we evaluated the associations with disease activity and functional indices. For this purpose, the variables of interest were categorized as follows: low $(<0.5 \mathrm{mg} / \mathrm{dl})$ or high $(\geq 0.5 \mathrm{mg} /$ dl) CRP; inactive disease $(\leq 1.3)$ or low/high/ very high ASDAS $(>1.3)$, BASDAI $\leq 4$ or $>4$; BASFI $\leq 1.5$ or $>1.5$ [13]; BASMI 0 or $>0$.

The study protocol was in compliance with the Declaration of Helsinki; written consent was obtained from each participant. The study was approved by the Institutional Review Board of

Table 3 Differences in clinical and MRI disease activity and functional indices between patients with and without pelvic extra-axial MRI abnormalities

\begin{tabular}{llll}
\hline & $\begin{array}{l}\text { Patients with no MRI pelvic abnormalities } \\
(\boldsymbol{n}=\mathbf{2 1}), \text { median (IQR) }\end{array}$ & $\begin{array}{l}\text { Patients with at least one MRI abnormality } \\
(\boldsymbol{n}=\mathbf{1 4}), \text { median (IQR) }\end{array}$ & $\boldsymbol{p}$ value \\
\hline $\begin{array}{c}\text { ASDAS- } \\
\text { CRP }\end{array}$ & $2.2(1.3-2.4)$ & $3.2(2.4-3.4)$ & 0.04 \\
BASDAI & $3(1.7-6.5)$ & $5(2.1-7)$ & 0.08 \\
BASMI & $1(0-1)$ & $2(1-3)$ & 0.1 \\
BASFI & $4(1-5)$ & $5(1.2-6)$ & 0.09 \\
SPARCC & $3(0-11.7)$ & $3(0-12)$ & 0.59 \\
\hline
\end{tabular}

$I Q R$ interquartile range, $A S D A S$ Ankylosing Spondylitis Disease Activity Score, CRP C-reactive protein, BASDAI Bath Ankylosing Spondylitis Disease Activity Index, BASMI Bath Ankylosing Spondylitis Metrology Index, BASFI Bath Ankylosing Spondylitis Funtional Index, SPARCC Spondyloarthritis Research Consortium of Canada Scoring System 
Table 4 Associations between the presence of extra-axial pelvic involvement at MRI and clinical features including sex, BMI, subset of axial $\mathrm{SpA}$, disease activity and functional indices

\begin{tabular}{lcc}
\hline & Odds ratio (95\% CI) & $\boldsymbol{p}$ value \\
\hline Sex & $0.47(0.09-2.3)$ & 0.35 \\
Male vs female & & \\
BMI & $1.07(0.2-5.6)$ & 0.91 \\
$>26$ vs $\leq 26$ & & \\
Disease duration & $0.54(0.09-2.3)$ & 0.64 \\
Male vs female & & \\
Subset & $1.08(0.2-5.6)$ & 0.91 \\
AS vs nr-axSpA & & 0.019 \\
ASDAS-CRP & $14.62(1.5-138)$ & 0.019 \\
$>2.1$ vs $\leq 2.1$ & & \\
BASDAI & & \\
$>4$ vs $\leq 4$ & $5.3(0.9-31)$ & \\
BASMI & & \\
$>0$ vs 0 & $15.9(0.8-307)$ & \\
BASFI & & \\
$>1.5$ vs $\leq 1.5$ & & \\
\hline B & & \\
\hline
\end{tabular}

$B M I$ body mass index, $A S$ ankylosing spondylitis, $n r$-axSp $A$ nonradiographic axial spondyloarthritis, ASDAS-CRP Ankylosing Spondylitis Disease Activity Score-C-reactive protein, BASDAI Bath Ankylosing Spondylitis Disease Activity Index, BASMI Bath Ankylosing Spondylitis Metrology Index, BASFI Bath Ankylosing Spondylitis Functional Index

the University of Molise (protocol no. 0001-092017).

\section{Statistical Analysis}

After testing for normally distributed data, descriptive results were reported as the mean (standard deviation, SD) or median (25th-75th percentile) value for continuous variables or the number (percentage) for categorical ones.
For continuous variables, the significance of the difference was determined using Student's $t$ test of unpaired data for normally distributed variables and the Mann-Whitney test of unpaired samples for non-normally distributed variables. Categorical variables were compared using the $\chi^{2}$ test or Fisher's exact test. Odds ratios were also calculated.

All statistical tests were two-sided at the 5\% level and performed using SPSS software (version 17.0; SPSS, Inc. Chicago, IL, USA).

\section{RESULTS}

35 patients (21 males and 14 females) with a mean age (SD) of 49 (12.7) years, a mean duration (SD) of symptoms of 5 (2.1) years and a mean disease duration (range) of $3(0-5)$ years were enrolled between 1 September 2020 and 31 March 2021. Of the 35 enrolled patients, only 3 $(8.5 \%)$ had pain in or limited function of one or both hips at clinical examination.

Table 1 shows the clinical, demographical and radiological features of the enrolled patients. Table 2 shows the MRI findings at extra-axial sites in our axial-SpA patients. Joint effusion at the hip joints was found in 11 (31.4\%) patients. Trochanteric enthesopathy/ bursitis and pubic osteitis were found in 2 patients (6.4\%) and in 1 patient (2.8\%), respectively. Bone marrow oedema was found in 1 patient and involved the right femoral head. No other abnormalities were found at other sites. Table 3 shows the differences in clinical and MRI disease activity and functional indices between patients with and without pelvic extra-axial MRI abnormalities. Median ASDAS-CRP was significantly higher in patients with extra-axial MRI abnormalities. Table 4 shows the associations between the presence of extra-axial abnormalities and the main clinical features, disease activity and functional indices. We found significant associations between the presence of extra-axial abnormalities, disease activity (ASDAS-CRP) and joint function (BASFI). Figure 1 shows some hip abnormalities found in our patients. No associations were found between the extent of SI bone marrow oedema (by SPARCC) and the presence of extra- 


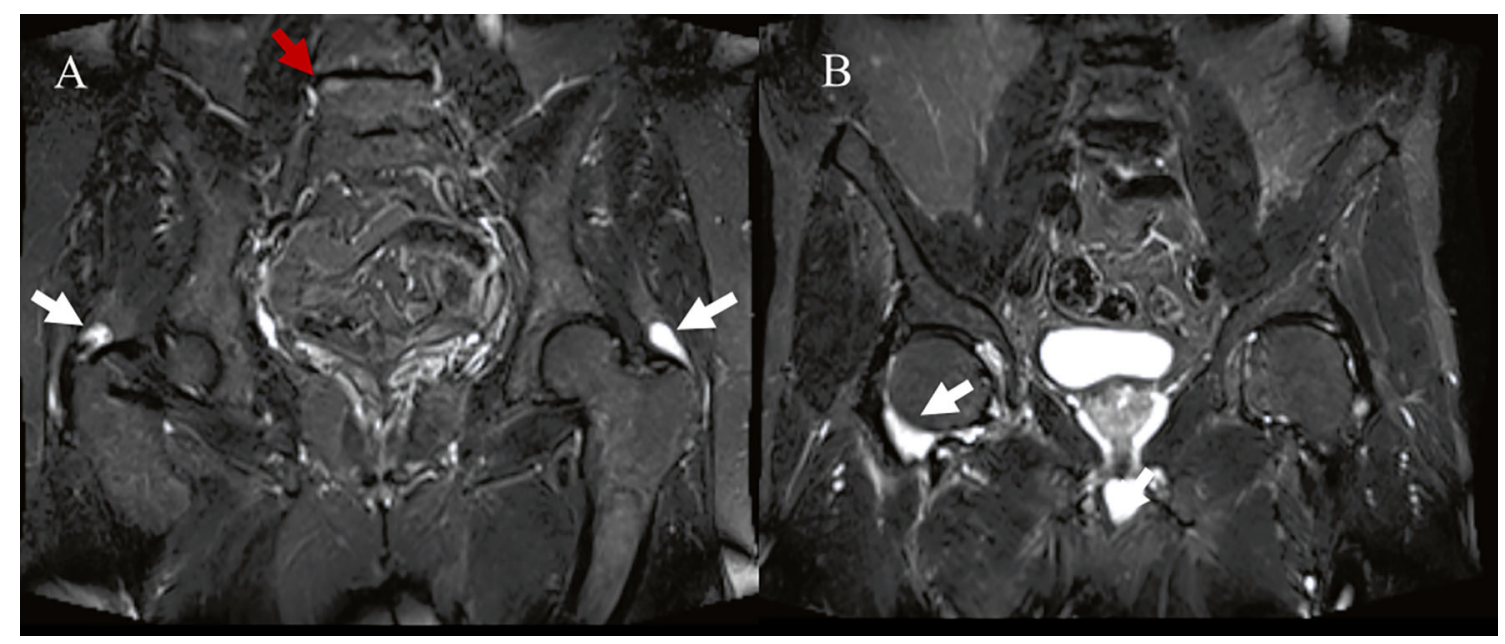

Fig. 1 A Bilateral trochanteric bursitis (white arrows) in a patient with ankylosing spondylitis. The red arrow shows an area of bone oedema in the vertebral angle as a further

axial abnormalities. It can be speculated that the two processes may not be strictly associated.

\section{DISCUSSION}

It is now widely recognized that MRI is a fundamental tool for the diagnosis and assessment of axial SpA patients, especially in the early phases of the disease [2]. This tool allows the detection of bone marrow oedema in spinal and SI joints as well as other acute and structural abnormalities at this level. However, at the same time, MRI can show the presence of some potential abnormalities at other sites that are not always considered in the global evaluation.

A Chinese study based on MRI showed that in 186 patients who had pain or limited hip function due to AS and for whom radiographic evidence of hip involvement was lacking, 168 (90\%) displayed positive results on MRI and were ultimately diagnosed with early-stage hip involvement. Younger age at onset, worse BASMI score and more active inflammation in the SI joints were significantly associated with the occurrence of hip involvement [14].

Moreover, Huang Zhen-Guo et al. demonstrated abnormalities in $86(74.1 \%)$ of 116 hips in 58 patients with AS. Joint effusion was observed in $73(62.9 \%)$. Enthesitis was also finding in the reported sequence. B Presence of intraarticular effusion of the right coxofemoral joint (white arrows) in a patient with ankylosing spondylitis

detected in 22 (19.0\%) hips, fatty accumulation of the bone marrow in $28(24.1 \%)$ hips, bone erosive destruction in $32(27.6 \%)$ hips and jointspace narrowing in 4 (3.4\%) hips [7].

In our study, we found hip effusion in about one-third of patients, while structural abnormalities were present in very few patients. One patient had hip bone marrow oedema, which, given its severity, was judged to be related to axial SpA. The rate of patients with abnormalities seems to be lower than in published data; however, disease duration was low in our study, and about half of the patients were classified as having nonradiographic SpA. In this light, we have demonstrated that MRI findings are present even in the "early" phases of the disease. Furthermore, and more interestingly, the presence of extra-axial pelvic abnormalities was associated with the probability of not having low disease activity or having the worst function. Moreover, our study specifically investigated other potential sites of inflammation.

Finally, our study showed that, beside involvement of the hip, other extraspinal entheseal sites are rarely involved in axial SpA.

This study has some limitations. First, the small sample size may have affected the rate of extraspinal involvement. Second, older axialSpA patients may have hip degenerative changes, and it is sometimes difficult to differentiate 
between a change caused by axial SpA and a change caused by osteoarthritis. However, the mean age of patients with extraspinal involvement was only 44 years. Finally, biologic treatment may reduce the presence of inflammation at different sites. This, in turn, may lead to an underestimation of the real prevalence of extraaxial lesions.

\section{CONCLUSION}

In conclusion, about one-third of the axial-SpA patients in our group had hip inflammatory changes, which is a much higher rate than the rate of hip involvement according to clinical symptoms, suggesting that MRI evaluation should be extended to the entire pelvis.

Further prospective studies are needed to evaluate if the early presence of acute inflammation or early structural changes at extra-axial sites may predict a bad outcome or lead to residual disease activity and the worst function, even in biologic-treated patients.

\section{ACKNOWLEDGEMENTS}

We want to thank the participants of the study.

Funding. No funding or sponsorship was received for this study or publication of this article. All authors had full access to all of the data in this study and take complete responsibility for the integrity of the data and accuracy of the data analysis.

Authorship. All named authors meet the International Committee of Medical Journal Editors (ICMJE) criteria for authorship for this article, take responsibility for the integrity of the work as a whole, and have given their approval for this version to be published.

Authorship Contributions. All authors have made substantial contributions to all of these sections: conception and design of the study, acquisition of data, analysis and interpretation of data, drafting the article, revising it critically for important intellectual content and final approval of the version to be submitted.

Disclosures. Fabio Massimo Perrotta, Silvia Scriffignano and Ennio Lubrano have nothing to disclose.

Compliance with Ethics Guidelines. All procedures performed in studies involving human participants were in accordance with the ethical standards of the institutional and/or national research committee and with the 1964 Helsinki Declaration and its later amendments or comparable ethical standards. Informed consent was obtained from all individual participants included in the study. The study was approved by the Institutional Review Board of the University of Molise.

Data Availability. The datasets generated during and/or analyzed during the current study are not publicly available but are available from the corresponding author on reasonable request.

Open Access. This article is licensed under a Creative Commons Attribution-NonCommercial 4.0 International License, which permits any non-commercial use, sharing, adaptation, distribution and reproduction in any medium or format, as long as you give appropriate credit to the original author(s) and the source, provide a link to the Creative Commons licence, and indicate if changes were made. The images or other third party material in this article are included in the article's Creative Commons licence, unless indicated otherwise in a credit line to the material. If material is not included in the article's Creative Commons licence and your intended use is not permitted by statutory regulation or exceeds the permitted use, you will need to obtain permission directly from the copyright holder. To view a copy of this licence, visit http://creativecommons.org/licenses/by$\mathrm{nc} / 4.0 /$. 


\section{REFERENCES}

1. Sieper J, Poddubnyy D. Axial spondyloarthritis. Lancet. 2017;390(10089):73-84. https://doi.org/10. 1016/S0140-6736(16)31591-4.

2. Rudwaleit M, van der Heijde D, Landewé R, Listing J, Akkoc N, Brandt J, et al. The development of Assessment of SpondyloArthritis international Society classification criteria for axial spondyloarthritis (part II): validation and final selection. Ann Rheum Dis. 2009;68:777-83.

3. Mandl P, Navarro-Compán V, Terslev L, Aegerter P, van der Heijde D, D'Agostino MA, Baraliakos X, Pedersen SJ, Jurik AG, Naredo E, Schueller-Weidekamm C, Weber U, Wick MC, Bakker PA, Filippucci E, Conaghan PG, Rudwaleit M, Schett G, Sieper J, Tarp S, Marzo-Ortega H, Østergaard M; European League Against Rheumatism (EULAR). EULAR recommendations for the use of imaging in the diagnosis and management of spondyloarthritis in clinical practice. Ann Rheum Dis. 2015;74(7): 1327-39.

4. Bray TJP, Jones A, Bennett AN, Conaghan PG, Grainger A, Hodgson R, Hutchinson C, Leandro M, Mandl P, McGonagle D, O'Connor P, Sengupta R, Thomas M, Toms A, Winn N, Hall-Craggs MA, Marzo-Ortega H, Machado PM; British Society of Spondyloarthritis (BRITSpA). Recommendations for acquisition and interpretation of MRI of the spine and sacroiliac joints in the diagnosis of axial spondyloarthritis in the UK. Rheumatol (Oxf). 2019;58(10):1831-38.

5. Vander Cruyssen B, Muñoz-Gomariz E, Font $P$, Mulero J, de Vlam K, Boonen A, Vazquez-Mellado J, Flores D, Vastesaeger N, Collantes E; ASPECTREGISPONSER-RESPONDIA Working Group. Hip involvement in ankylosing spondylitis: epidemiology and risk factors associated with hip replacement surgery. Rheumatol (Oxf). 2010;49(1):73-81.

6. Vander Cruyssen B, Vastesaeger N, Collantes-Estévez E. Hip disease in ankylosing spondylitis. Curr Opin Rheumatol. 2013;25(4):448-54.
7. Huang ZG, Zhang XZ, Hong W, Wang GC, Zhou HQ, Lu X, Wang W. The application of MR imaging in the detection of hip involvement in patients with ankylosing spondylitis. Eur J Radiol. 2013;82(9):1487-93.

8. Garret S, Jenkinson T, Whitelock H, Gaisford P, Calin A. A new approach to defining disease status in ankylosing spondylitis: the Bath Ankylosing Spondylitis Activity Index. J Rheumatol. 1994;21: 2286-91.

9. Machado P, Landewé R, Lie E, Kvien TK, Braun J, Baker D et al. Assessment of SpondyloArthritis international Society. Ankylosing Spondylitis Disease Activity Score (ASDAS): defining cut-off values for disease activity states and improvement scores. Ann Rheum Dis 2011;70:47-53.

10. van der Linden S, Valkenburg HA, Cats A. Evaluation of diagnostic criteria for ankylosing spondylitis. A proposal for modification of the New York criteria. Arthritis Rheum. 1984;27(4):361-8

11. Maksymowych WP, Inman RD, Salonen D, Dhillon SS, Williams M, Stone M, Conner-Spady B, Palsat J, Lambert RG. Spondyloarthritis research Consortium of Canada magnetic resonance imaging index for assessment of sacroiliac joint inflammation in ankylosing spondylitis. Arthritis Rheum. 2005;53(5):703-9.

12. Huang ZG, Zhang XZ, Hong W, Wang GC, Zhou $\mathrm{HQ}, \mathrm{Lu} \mathrm{X}$, et al. The application of MR imaging in the detection of hip involvement in patients with ankylosing spondylitis. Eur J Radiol. 2013;82(9): 1487-93.

13. Wariaghli G, Allali F, Berrada K, Idrissi Z, Hmamouchi I, Abouqal R, Hajjaj-Hassouni N. Normative values for the Bath Ankylosing Spondylitis Functional Index in the general population compared with ankylosing spondylitis patients in Morocco. BMC Musculoskelet Disord. 2012;21(13):40.

14. Chen D, Yuan S, Zhan Z, Xiao Y, Li H, Liang L, Yang $X$. Early-stage hip involvement in patients with ankylosing spondylitis: a Chinese study based on magnetic resonance imaging. Mod Rheumatol. 2016;26(6):933-9. 